\title{
ANALISIS GENDER DAN INTELLECTUAL INTELLIGENCE TERHADAP KREATIVITAS
}

\author{
Mardhiah Masril $^{1}$, Oskah Dakhi ${ }^{2}$, Torkis Nasution ${ }^{3}$, Ambiyar $^{4}$ \\ ${ }^{1}$ Sistem Komputer Universitas Putra Indonesia "YPTK” Padang, \\ Jalan Raya Lubuk Begalung, Padang \\ ${ }^{2}$ Teknik Informatika STMIK Budidarma, Jalan Sisingamangaraja, Siti Rejo I, Medan \\ ${ }^{3}$ Teknik Informatika STMIK Amik Riau, Jalan Purwodadi Indah, Pekanbaru \\ ${ }^{4}$ Pendidikan Teknologi dan Kejuruan Universitas Negeri Padang, \\ Jalan Prof. Dr. Hamka, Air Tawar, Padang \\ 'e-mail: mardhiah_m@upiyptk.ac.id
}

\begin{abstract}
Abstrak
Penelitian bertujuan untuk mengetahui hubungan antara perbedaan gender dan intellectual intelligence terhadap kreativitas siswa sekolah dasar. Sampel penelitian berjumlah 60 siswa yang dipilih secara simple random sampling. Instrumen yang digunakan yaitu Coloured Progressive Matrices dan Figural Creativity Test untuk menentukan tingkat intellectual intelligence dan kreativitas siswa. Teknik analisis data menggunakan analisis korelasi. Hasil analisis menunjukkan bahwa: kemampuan intellectual intelligence berkaitan dengan kemampuan untuk berkreativitas; tidak ditemukan perbedaan gender terhadap kemampuan berkreativitas; dan analisis korelasi berganda terhadap kemampuan intellectual intelligence dan perbedaan gender menunjukkan tidak ada hubungan dengan kemampuan kreativitas siswa.
\end{abstract}

Kata Kunci: kreativitas, intellectual intelligence, gender, korelasi.

\section{Abstract}

The research aimed to determine the relationship between gender differences and intellectual intelligence on the creativity of elementary school students. The research sample consisted of 60 students who were selected by simple random sampling. The instruments used were Colored Progressive Matrices and Figural Creativity Test to determine the level of intellectual intelligence and creativity of students. The data analysis technique used correlation analysis. The results of the analysis showed that: intellectual intelligence ability was related to the ability to be creative; no gender differences were found on creativity skills; and multiple correlation analysis on intellectual intelligence abilities and gender differences showed no relationship with students' creative abilities.

Keywords: creativity, intellectual intelligence, gender, correlation.

\section{PENDAHULUAN}

Studi tentang kreativitas telah menjadi aspek penting dalam sistem pendidikan nasional karena salah satu elemen penting dalam tujuan pendidikan nasional adalah mengembangkan potensi siswa untuk menjadi manusia kreatif. Kreativitas adalah kemampuan untuk membuat kombinasi baru berdasarkan data, informasi atau unsur-unsur yang ada (Munandar, 1999). Kreativitas dapat juga diartikan sebagai kemampuan menciptakan kombinasi dari hal-hal yang sudah ada 
(Dariyo, 2008). Kreativitas bisa muncul atas dasar pengetahuan yang diperoleh dan sebagai bentuk imajinasi yang mengarah ke keahlian (psikomotor) dan prestasi (Arpan, dkk., 2016; Cassia, dkk., 2015; Kim, 2011).

Beberapa faktor yang menyebabkan munculnya variasi atau perbedaan kreativitas terhadap seseorang seperti intellectual intelligence dan gender. Intellectual intelligence secara umum adalah kemampuan seseorang untuk menyesuaikan, belajar atau berpikir secara abstrak (Wechsler, 1958). Intellectual intelligence adalah kemampuan untuk memahami, bertindak secara tepat pada situasi yang dihadapi, kemampuan untuk berpikir secara abstrak, serta kemampuan untuk memahami dan memikirkan ide-ide abstrak dan simbol (Pierson, dkk., 2012). Intellectual intelligence adalah kemampuan untuk belajar (Williams, 2013). Intellectual intelligence juga berkaitan dengan kemampuan untuk beradaptasi dengan situasi dan rintangan serta kemampuan untuk menyesuaikan diri (Tyler, 1956). Seseorang dengan tingkat intellectual intelligence tinggi mudah untuk belajar dari pengalaman.

Hubungan antara intellectual intelligence dan kreativitas adalah masalah yang sangat menarik untuk dibahas. Intelektual memiliki hubungan dengan kreativitas (Plucker dan Esping, 2015). Namun, terdapat hubungan yang lemah antara kreativitas dan intelektual untuk intelligence quotient (IQ) yang nilainya lebih dari 119 daripada IQ yang nilainya kurang dari 120 (Guignard, dkk., 2015). Sedangkan perbedaan kreativitas jika dilihat dari faktor gender terdapat beberapa pendapat. Terdapat beberapa perbedaan dalam kreativitas antara laki-laki dan perempuan dalam kinerja perilaku pada tugas-tugas kognisi normatif (Abraham, 2015). Laki-laki memiliki kreativitas lebih tinggi daripada perempuan (Proudfoot, dkk., 2015). Ada perbedaan tingkat kreativitas antara laki-laki dan perempuan saat menghadapi tugas-tugas generatif (Abraham, dkk., 2013). Menurut beberapa hasil penelitian lainnya, terdapat perbedaan kreativitas antara laki-laki dengan perempuan (He dan Wong, 2011; Lin, dkk., 2012; Baer, 2010).

Banyak penelitian yang telah dilakukan terkait dengan hubungan antara intellectual intelligence dengan kreativitas dan hubungan antara gender dan kreativitas namun masih dilakukan secara terpisah, masih sedikit informasi yang 
membahas hubungan antara intellectual intelligence dan gender terhadap kreativitas secara bersamaan. Berdasarkan permasalahan yang telah diuraikan, maka tujuan dari penelitian yaitu untuk mengetahui apakah terdapat hubungan antara intellectual intelligence, gender, dan kreativitas siswa.

\section{METODE}

Penelitian dilakukan pada siswa sekolah dasar swasta di Kota Padang, dengan total sampel sebanyak 60 siswa dari kelas 4 sekolah dasar (usia 10-12 tahun) yang dipilih secara simple random sampling. Instrumen penelitian yang digunakan adalah Coloured Progressive Matrices (CPM) yang berfungsi untuk mengukur intellectual intelligence dan Tes Kreativitas Figural (TKF) sebagai alat ukur untuk mengetahui tingkat kreativitas. CPM tersedia dalam dua bentuk yaitu buku dan gambar yang dicetak dengan 36 item. Setiap item terdiri dari gambar besar yang tidak lengkap. Siswa bertugas untuk memilih salah satu dari pilihan gambar yang disediakan sebagai jawaban untuk melengkapi gambaran besar. Pada dasarnya, tes CPM dimaksudkan untuk mengungkapkan pemikiran logis, keterampilan, dan kemampuan untuk mencari, memahami hubungan keseluruhan, dan bagian-bagiannya.

Prosedur pengukuran intellectual intelligence yang dilakukan mengikuti tahapan berikut: pada uji CPM para siswa diminta untuk menyelesaikan 3 set pertanyaan yaitu A, AB, dan B. Masing-masing set terdiri dari 12 pertanyaan. Skor mentah diperoleh dengan memberikan nilai satu untuk setiap jawaban yang benar dan nol untuk setiap jawaban yang salah. Skor mentah selanjutnya diubah menjadi persentil sesuai dengan usia kronologis dan berikutnya akan diklasifikasikan sebagai kelas dan kapasitas intellectual intelligence. Klasifikasi tingkat IQ (Hendrik, dkk., 2019) dapat dilihat pada Tabel 1.

TKF mengukur kemampuan siswa dalam membentuk kombinasi baru dari unsur yang diberikan, sehingga dapat dilihat aspek kelancaran, fleksibilitas, dan orisinalitas dalam memberikan ide-ide dan kemampuan untuk mengembangkan, menguraikan dan memperkaya ide (elaborasi). Tes kreativitas figural terdiri dari tiga kegiatan. Kegiatan pertama adalah konstruksi gambar, siswa disajikan titik 
hitam untuk selanjutnya membuat gambar dari titik hitam tersebut dan memberikan judul. Kegiatan kedua adalah melengkapi gambar. Kegiatan ketiga, siswa disajikan garis paralel atau lingkaran yang digunakan untuk membuat gambar.

Tabel 1 Tingkat IQ berdasarkan standar Standford Binet

\begin{tabular}{ccc}
\hline CPM & $\begin{array}{c}\text { Kisaran IQ berdasarkan } \\
\text { Standar Standford Binet }\end{array}$ & Klasifikasi \\
\hline Grade I & $120-139$ & Superior \\
Grade II & $110-119$ & Diatas rata-rata \\
Grade III & $90-109$ & Rata-rata \\
Grade IV & $80-89$ & Dibawah rata-rata \\
Grade V & $68-79$ & Borderline retardasi mental \\
\hline
\end{tabular}

Prosedur pengukuran kreativitas, TKF menilai 4 aspek kreativitas yaitu kelancaran, fleksibilitas, orisinalitas, dan elaborasi. Nilai baku yang diperoleh dari penilaian terhadap empat aspek tersbut selanjutnya dikonversi ke nilai standar kemudian jumlah nilai mentah menjadi skor kreatif quotient. Selanjutnya hasil tes kreativitas diklasifikasikan menjadi empat level (Hendrik, dkk., 2020), sesuai dengan Tabel 2.

Tabel 2 Klasifikasi Level Kreativitas Figural

\begin{tabular}{cc}
\hline Kisaran Skor Kreatif Quotient & Klasifikasi \\
\hline$>=120$ & Superior (SR) \\
$111-119$ & Diatas rata-rata (HAVR) \\
$91-110$ & Rata-rata (AVR) \\
$80-90$ & Dibawah rata-rata (LAVR) \\
\hline
\end{tabular}

Teknik analisis data korelasi pearson digunakan untuk mengetahui korelasi antara intellectual intelligence dan kreativitas siswa, serta antara gender dan kreativitas siswa. Sedangkan untuk mengetahui korelasi antara intellectual intelligence dan gender terhadap kreativitas siswa digunakan teknik analisis data korelasi berganda. Analsis data dilakukan dengan bantuan software SPSS. 


\section{HASIL DAN PEMBAHASAN}

Hasil penelitian menjelaskan hubungan antara intellectual intelligence dan gender dengan tingkat kreativitas siswa.

\section{Kreativitas Siswa Berdasarkan Intellectual Intelligence}

Distribusi frekuensi tingkat intellectual intelligence semua siswa berdasarkan level CPM dapat dilihat pada Tabel 3.

Tabel 3 Data Deskriptif Tingkat Intellectual Intelligence Siswa

\begin{tabular}{ccc}
\hline Tingkat CPM & Frekuensi & Persentase (\%) \\
\hline Grade I & 18 & 30,0 \\
Grade II & 24 & 40,0 \\
Grade III & 15 & 25,0 \\
Grade IV & 2 & 3,3 \\
Grade V & 1 & 1,7 \\
\hline Total & $\mathbf{6 0}$ & $\mathbf{1 0 0 , 0}$ \\
\hline
\end{tabular}

Berdasarkan Tabel 3, distribusi jumlah siswa berdasarkan tingkat intellectual intelligence pada Grade II adalah yang terbesar, dilanjutkan dengan Grade I, kemudian dengan Grade III dan Grade IV. Sedangkan Grade V adalah yang paling sedikit frekuensi jumlah siswanya.

Tabel 4 menunjukkan distribusi tingkat kreativitas siswa berdasarkan grade intellectual intelligence siswa.

Tabel 4 Tingkat Kreativitas Siswa Berdasarkan Tingkat Intellectual Intelligence

\begin{tabular}{|c|c|c|c|c|c|}
\hline \multirow{2}{*}{$\begin{array}{l}\text { CPM } \\
\text { Level }\end{array}$} & \multicolumn{4}{|c|}{ TKF Level } & \multirow{2}{*}{ Total } \\
\hline & SR & HAVR & AVR & LAVR & \\
\hline Grade I & 1 & 1 & 12 & 4 & 18 \\
\hline Grade II & 0 & 3 & 18 & 3 & 24 \\
\hline Grade III & 0 & 1 & 8 & 6 & 15 \\
\hline Grade IV & 0 & 0 & 0 & 2 & 2 \\
\hline Grade V & 0 & 0 & 0 & 1 & 1 \\
\hline Total & 1 & 5 & 38 & 16 & 60 \\
\hline
\end{tabular}


Berdasarkan Tabel 4, tidak terdapat siswa dengan Level TKF superior pada Grade II, III, IV, dan V. Hanya terdapat 1 orang siswa dengan Level TKF Superior dari keseluruhan sampel. Tingkat kreativitas terbesar adalah pada level Rata-rata (melebihi setengah dari populasi sampel) dan diikuti level Dibawah ratarata.

Hasil tes intellectual intelligence dan kreativitas siswa selanjutnya dianalisis dengan korelasi pearson dan hasilnya dapat dilihat pada Tabel 5.

Tabel 5 Korelasi antara Intellectual Intelligence dan Hasil Tes TKF

\begin{tabular}{lll}
\hline & \multicolumn{2}{c}{ TKF } \\
\hline \multirow{2}{*}{ CPM } & Pearson Correlation & $0,295 *$ \\
& Sig. (2-tailed) & 0,022 \\
& $\mathrm{~N}$ & 60 \\
\hline *. Korelasi adalah signifikan pada tingkat 0,05 & (2-tailed).
\end{tabular}

Tabel 5 menunjukkan bahwa analisis korelasi antara intellectual intelligence dan kreativitas memiliki nilai signifikansi 0,022 ( $\mathrm{p}<0,05)$. Sehingga dapat dinyatakan terdapat korelasi positif antara intellectual intelligence dan tingkat kreativitas siswa.

\section{Kreativitas Siswa Berdasarkan Gender}

Sampel $(\mathrm{N}=60)$ terdiri dari $46,7 \%$ laki-laki dan 53,3\% perempuan. Distribusi sampel berdasarkan gender dapat dilihat pada Tabel 6.

\section{Tabel 6 Distribusi Sampel Berdasarkan Gender}

\begin{tabular}{cc}
\hline Gender & Jumlah \\
\hline Laki-laki & 28 \\
Perempuan & 32 \\
\hline Jumlah & $\mathbf{6 0}$ \\
\hline
\end{tabular}

Distribusi siswa dengan tingkat TKF berdasarkan gender yaitu: 1 perempuan pada tingkat Superior; 1 laki-laki dan 4 perempuan pada tingkat Diatas rata-rata; 22 laki-laki dan 16 perempuan pada tingkat Rata-rata; serta 5 laki-laki dan 11 perempuan pada tingkat Dibawah rata-rata. Analisis korelasi antara gender dan kreativitas siswa memiliki nilai signifikansi 0,858 ( $p>0,05)$. Sehingga dapat 
disimpulkan tidak ada perbedaan yang signifikan terhadap tingkat kreativitas siswa jika dilihat dari aspek gender.

\section{Kreativitas Siswa Berdasarkan Intellectual Intelligence dan Gender}

Tingkat kreativitas siswa jika diklasifikasikan berdasarkan intellectual intelligence dan gender dapat dilihat pada Tabel 7.

Tabel 7 Tingkat Kreativitas Berdasarkan Intellectual Intelligence dan Gender

\begin{tabular}{ccccc}
\hline \multirow{2}{*}{ TKF Tingkat } & \multirow{2}{*}{ CPM Tingkat } & \multicolumn{2}{c}{ Gender } & \multirow{2}{*}{ Total } \\
\cline { 3 - 4 } & & Laki-laki & Perempuan & \\
\hline Superior & Grade I & 0 & 1 & 1 \\
\hline \multirow{3}{*}{ Diatas rata-rata } & Grade I & 0 & 1 & 1 \\
& Grade II & 1 & 2 & 3 \\
& Grade III & 0 & 1 & 1 \\
\hline \multirow{3}{*}{ Rata-rata } & Grade I & 8 & 4 & 12 \\
& Grade II & 10 & 8 & 18 \\
& Grade III & 4 & 4 & 8 \\
\hline \multirow{5}{*}{ Dibawah rata-rata } & Grade I & 1 & 3 & 4 \\
& Grade II & 1 & 2 & 3 \\
& Grade III & 1 & 5 & 6 \\
& Grade IV & 1 & 1 & 2 \\
& Grade V & 1 & 0 & 1 \\
\hline
\end{tabular}

Tabel 7 menunjukkan distribusi tingkat kreativitas siswa berdasarkan gender. Hanya terdapat siswa perempuan dengan Level TKF Superior. Jumlah sebaran terbesar untuk sampel baik laki-laki maupun perempuan adalah pada level TKF Rata-rata dan diikuti level TKF Dibawah rata-rata.

Analisis korelasi berganda antara intellectual intelligence dan gender terhadap kreativitas siswa memiliki nilai sig. F change 0,072 ( $\mathrm{p}>0,05)$. Sehingga dapat disimpulkan bahwa tidak ada korelasi antara intellectual intelligence dan perbedaan gender siswa terhadap tingkat kreativitas siswa. 


\section{Pembahasan}

Berdasarkan hasil analisis korelasi gender terhadap kreativitas dapat dinyatakan tidak terdapat korelasi yang signifikan antara perbedaan kreativitas siswa laki-laki dan siswa perempuan. Hasil tersebut konsisten dengan penelitian lainnya yang juga menyatakan tidak terdapat perbedaan kreativitas siswa laki-laki dengan siswa perempuan dan siswa laki-laki lebih cenderung kreatif dalam berdiskusi, membangun, mencoba ide baru di dunia nyata, sedangkan perempuan juga cenderung kreatif dalam berdiskusi, merancang, dan menciptakan (Potur dan Barkul, 2009). Penelitian lainnya juga menyatakan tidak ada perbedaan gender bawaan dalam berkreativitas (Baer dan Kaufman, 2008). Sedangkan hasil penelitian lainnya menyatakan bahwa tidak ada perbedaan gender pada pemikiran divergen (Sayed, dkk., 2013). Namun hasil penelitian bertolak belakang dengan penelitian lainnya yang menyatakan bahwa terdapat perbedaan kreativitas jika dilihat dari segi gender. Siswa perempuan di sekolah menengah pertama lebih kreatif dari aspek fluency, fleksibilitas, dan originality dibandingkan siswa lakilaki (Cheung dan Lau, 2010).

Berdasarkan hasil analisis selanjutnya dapat dinyatakan terdapat hubungan positif antara intellectual intelligence dan tingkat kreativitas siswa. Hasil analisis tersebut konsisten dengan hasil penelitian lainnya yang menunjukkan terdapat korelasi antara intelligence dengan kreativitas (Benedek, dkk., 2014). Pendapat lainnya juga mengemukakan pendapat yang sama bahwa kemampuan intelektual pada siswa sekolah dasar dengan rentang usia 10-12 tahun memiliki relasi dengan kemampuan berpikir kreatif terutama pada kemampuan elaborasi dan keunikan yang merupakan bagian dari kreativitas (Hendrik, dkk., 2019).

Kreativitas siswa bisa saja berbeda pada berbagai jenis sampel penelitian karena kreativitas merupakan suatu hal yang sangat kompleks dan dapat dipengaruhi oleh beberapa hal. Kreativitas melibatkan kesempatan pendidikan, kesempatan berlatih, pengaruh lingkungan keluarga, budaya, dan gender (Ulger dan Morsunbul, 2016). Untuk meningkatkan kreativitas siswa, maka perlu adanya pengembangan metode pembelajaran terintegrasi dengan teknologi yang menjadi 
tren abad ke-21 sehingga mampu meningkatkan kreativitas siswa (Masril, dkk., 2019).

\section{SIMPULAN}

Berdasarkan hasil penelitian, disimpulkan bahwa terdapat korelasi positif antara intellectual intelligence dan kreativitas siswa, namun hasil analisis korelasi terhadap variabel lainnya menyatakan bahwa tidak ada perbedaan yang signifikan terhadap tingkat kreativitas jika dilihat dari aspek gender. Sedangkan analisis korelasi berganda menunjukkan bahwa tidak ada hubungan antara intellectual intelligence dan perbedaan gender terhadap tingkat kreativitas siswa.

\section{DAFTAR PUSTAKA}

Abraham, A. 2015. Gender and Creativity: An Overview of Psychological and Neuroscientific Literature. Brain Imaging and Behavior, 10(2): 609-618.

Abraham, A., Thybusch, K., \& Pieritz, K. 2013. Gender Differences in Creative Thinking: Behavioral and FMRI Findings. Brain Imaging and Behavior, 8(1): 39-51.

Arpan, M., Sulistiyarini, D., \& Santoso, D. 2016. Effect of Motivation and Creativity on Students' Psychomotor Ability. Journal of Education, Teaching and Learning, 1(2): 71-75.

Baer, J. 2010. Gender Differences in the Effects of Anticipated Evaluation on Creativity. Creativity Research Journal, 10(1): 37-41.

Baer, J. \& Kaufman, J. C. 2008. Gender Differences in Creativity. Journal of Creative Behavior, 42(2): 75-105.

Benedek, M., Jauk, E., Sommer, M., Arendasy, M., \& Neubauer, A. C. 2014. Intelligence, Creativity, and Cognitive Control: The Common and Differential Involvement of Executive Functions in Intelligence and Creativity. Intelligence, 46(1):73-83.

Cassia, T. D., Pontificia, N., Catolica, U., \& Paulo, S. 2015. Intelligence and Creativity: Relationships and Their Implications for Positive Psychology. Psico-USF Bragança Paulista, 20(2): 195-206.

Cheung, P. C. \& Lau, S. 2010. Gender Differences in the Creativity of Hong Kong School Children: Comparison by Using the New Electronic Wallach Kogan Creativity Tests. Creativity Research Journal, 22(2):194-199.

Dariyo, A. 2008. Psikologi Perkembangan Dewasa Muda. Jakarta: Gramedia.

Guignard, J., Kermarrec, S., \& Tordjman, S. 2015. Relationships between Intelligence and Creativity in Gifted. Learning and Individual Differences, 52(C): 209-215.

He, W. \& Wong, W. 2011. Gender Differences in Creative Thinking Revisited: Findings from Analysis of Variability. Personality and Individual 
Differences, 51(7): 807-811.

Hendrik, B., Ali, N. M., \& Nayan, N. M. 2020. Robotic Technology for Figural Creativity Enhancement: Case Study on Elementary School. International Journal of Advanced Computer Science and Applications, 11(1): 536-543.

Hendrik, B., Ali, N. M., Sulaiman, R., Masril, M., \& Fikri, H. T. 2019. Relationship between Intellectual Intelligence, Figural Creativity, and Innovation. Advances in Social Science, Education and Humanities Research, 229(1): 545-555.

Kim, K. H. 2011. The Creativity Crisis: The Decrease in Creative Thinking Scores on the Torrance Tests of Creative Thinking. Creativity Research Journal, 23(4): 285-295.

Lin, W., Chen, H., \& Wang, J. 2012. The Relations of Gender and Personality Traits on Different Creativities: A Dual-Process Theory Account. Psychology of Aesthetics, Creativity, and the Arts, 6(2): 112-123.

Masril, M., Hendrik, B., Fikri, H. T., Hazidar, A. H., Priambodo, B., Naf'an, E., Handriani, I., Putra, Z. P., \& Nseaf, A. K. 2019. The Effect of Lego Mindstorms as an Innovative Educational Tool to Develop Students' Creativity Skills for a Creative Society. Journal of Physics: Conference Series, 1339(2019): 1-9.

Munandar, U. 1999. Pengembangan Kreativitas Anak Berbakat. Jakarta: Rineka Cipta.

Pierson, E. E., Kilmer, L. M., Rothlisberg, B. A., \& Mcintosh, D. E. 2012. Tests in the Identification of Giftedness. Journal of Psychoeducational Asessment, 30(1): 10-24.

Plucker, J. A. \& Esping, A. 2015. Intelligence and Creativity: A Complex but Important Relationship. Asia Pacific Education Review, 16(2): 153-159.

Potur, A. A. \& Barkul, O. 2009. Gender and Creative Thinking in Education: A Theoretical and Experimental Overview. A|Z ITU Journal of Faculty of Architecture, 6(2): 44-57.

Proudfoot, D., Kay, A. C., Koval, C. Z., Hitchcock, A., Dylan, B., \& Wright, F. L. 2015. A Gender Bias in the Attribution of Creativity: Archival and Experimental Evidence for the Perceived Association Between Masculinity and Creative Thinking. Psychological Science, 26(11): 1751-1761.

Sayed, E. M., Hassan, A., \& Mohamed, H. 2013. Gender Differences in Divergent Thinking: Use of the Test of Creative Thinking-Drawing Production on an Egyptian Sample. Creativity Research Journal, 25(1): 37-41.

Tyler, L. E. 1956. The Psychology of Human Differences. New Work: Appleton.

Ulger, K. \& Morsunbul, U. 2016. The Differences in Creative Thinking: The Comparison of Male and Female Students. The Online Journal of Counseling and Education, 5(4): 1-12.

Wechsler, D. 1958. The Measurement and Appraisal of Adult Intelligence. Baltimore: Williams and Wilkins.

Williams, R. L. 2013. Intelligence Overview of the Flynn Effect. Intelligence, 41(6): 753-764. 